\title{
Linking vegetable preferences, health and local food systems through community-supported agriculture
}

\author{
Jennifer L Wilkins ${ }^{1, *}$, Tracy J Farrell ${ }^{2}$ and Anusuya Rangarajan ${ }^{3}$ \\ 'Department of Public Health, Food Studies and Nutrition, 417 Sims Hall, Syracuse University, Syracuse, NY $13244-$ \\ 3240, USA: ${ }^{2}$ Division of Nutritional Sciences, Cornell University, Ithaca, NY, USA: ${ }^{3}$ Department of Horticulture, \\ Cornell University, Ithaca, NY, USA
}

Submitted 15 March 2014: Final revision received 28 January 2015: Accepted 1 February 2015: First published online 31 March 2015

\begin{abstract}
Objective: The objective of the present study was to explore the influence of participation in community-supported agriculture (CSA) on vegetable exposure, vegetable intake during and after the CSA season, and preference related to locally produced vegetables acquired directly from CSA growers.

Design: Quantitative surveys were administered at three time points in two harvest seasons to four groups of CSA participants: new full-paying, returning full-paying, new subsidized and returning subsidized members. Questionnaires included a vegetable frequency measure and measures of new and changed vegetable preference. Comparisons were made between new and returning CSA members and between those receiving subsidies and full-paying members.

Setting: The research was conducted in a rural county in New York, USA.

Subjects: CSA members who agreed to participate in the study.

Results: Analysis was based on 151 usable questionnaires. CSA participants reported higher intake of eleven different vegetables during the CSA season, with a sustained increase in some winter vegetables. Over half of the respondents reported trying at least one, and up to eleven, new vegetables. Sustained preferences for CSA items were reported.

Conclusions: While those who choose to join a CSA may be more likely to acquire new and expanded vegetable preferences than those who do not, the CSA experience has the potential to enhance vegetable exposure, augment vegetable preference and increase overall vegetable consumption. Dietary patterns encouraged through CSA participation can promote preferences and consumer demand that support local production and seasonal availability. Emphasis on fresh and fresh stored locally produced vegetables is consistent with sustainable community-based food systems.
\end{abstract}

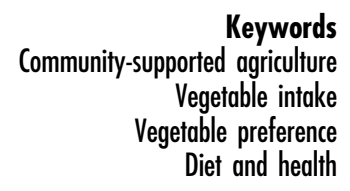

Community-supported agriculture (CSA), an emerging community-based food system structure, offers potential to simultaneously address dietary inadequacies and sustainability. While per capita vegetable intake in the USA varies from state to state, overall intake is below the recommended number of daily servings ${ }^{(1)}$. Only about $40 \%$ of Americans consume at least five servings of fruits and vegetables daily ${ }^{(2)}$. The typical American diet provides less than two-thirds (59\%) of the amount of fruits and vegetables recommended by the US Dietary Guidelines ${ }^{(3)}$. Guenther et al. found that mean intakes by all sex-age groups were lower than recommended for total vegetables and for all vegetable subgroups except starchy vegetables, among eleven of the fifteen sex-age groups ${ }^{(2)}$. Mean intakes of dark green vegetables, orange vegetables and legumes were at most one-third of recommended amounts. Inadequate fruit and vegetable intake is associated with lower socio-economic position and education levels ${ }^{(4-6)}$.

Vegetable-rich diets are associated with lowered risk of several chronic diseases and can help achieve and maintain a healthy weight ${ }^{(7)}$. Meta-analyses have found an inverse relationship between the risk for cancers of the breast, oesophagus, lung, stomach and colorectum and vegetable intake ${ }^{(8)}$, as well as a lower risk of stroke associated with higher intake of fruits and vegetables ${ }^{(9)}$. Inverse associations have been shown between fruit and vegetable intake and incidence of both coronary artery disease $^{(10,11)}$ and diabetes (particularly among women) $)^{(12)}$. 
CSA - a farmer-to-consumer arrangement where members (or 'shareholders') pay in advance for a weekly supply of seasonally harvested produce ${ }^{(13)}$ - has emerged and proliferated across the USA. CSA, along with farmers' markets, farm to school programmes, food hubs, community gardens and community kitchens, are considered elements of community-based and sustainable food systems.

Virtually unknown in the USA until the mid-1980s, an estimated 6000 to 6500 CSA schemes exist today ${ }^{(13,14)}$. CSA is considered a 'win-win' for farmers and consumers. Farmers gain a direct market while members have greater access to seasonal and diverse local foods, and opportunities to know and trust the source of their foods ${ }^{(15-17)}$.

Given the often-substantial upfront cost involved in CSA membership (full shares can cost between \$US 450.00 and \$US 750.00), people with lower incomes are less likely to participate. As a result, CSA operators are developing creative methods (sliding-scale share costs, instalment payment options and subsidization of shares with additional funds) to reach people with lower incomes. In a mail survey of CSA managers, Guthman et al. found that $83 \%$ of respondents had tried at least one strategy to attract low-income participants ${ }^{(15,18)}$. Without sliding-scale share prices, or share subsidy programmes, studies have found 'limited socio-economic diversity among CSA members, with most being middle-class, urban, white and highly educated ${ }^{(19)}$, often creating a considerable income gap between the CSA farmers and the members they feed $^{(20)}$.

In addition to providing weekly harvest shares, CSA typically exposes members to unfamiliar vegetables and provides guidance on vegetable selection, preparation and storage. CSA members cite access to fresh, high quality, organic produce as a key benefit of CSA participation ${ }^{(21,22)}$ and report an increase in the amount and variety of produce they consume. The role of exposure in the development and expansion of food preferences has been studied extensively since early work by Zajonc ${ }^{(23)}$. For novel foods, such as some of the vegetables offered in a CSA, studies suggest that repeated exposure may be required to develop a new preference ${ }^{(24,25)}$. CSA participants are likely to have repeated exposure to vegetables concentrated within their harvest periods. CSA farmers' decisions about which vegetables (and which vegetable varieties) to plant and provide in weekly shares are influenced more by member interests, natural resources and agronomic skills than by market forces influencing produce vegetable availability in supermarkets. With increased exposure to novel CSA vegetables, participants are more likely to increase preference for and purchase of these vegetables.

The purpose of the present study was to explore the influence of CSA participation on vegetable exposure, vegetable intake during and after the CSA season and change in vegetable preference and use. Variables of interest included changes in: quantity and variety of vegetables consumed; vegetable preferences; and self-efficacy related to vegetable preparation. Because evidence suggests that lower vegetable intake is associated with lower incomes ${ }^{(6)}$, and individuals with average or higher incomes are more likely to meet dietary recommendations for fruits and vegetables than people with lower incomes ${ }^{(26)}$, we were particularly interested in the impact of CSA participation on members from lower-income households.

\section{Methods}

\section{Study participants}

Study participants were recruited from a 1000-shareholder CSA serving members within and north of New York City, and two CSA farms in upstate New York with a combined total of 250 shareholders. There were two urban share pickup sites in low-income neighbourhoods in uptown Manhattan for the large metropolitan New York City CSA and choice of on-farm or farmers' market pickup sites for the upstate CSA. CSA farms selected for inclusion in the present study were known to deliberately offer subsidized or low-cost shares. CSA managers assisted with study participant recruitment by distributing study information and invitations to all members via email or in person at pre-CSA season meetings. Participants were included regardless of family status, e.g. single, married, CSA members with or without children, or cohabitants. Enrolment in the study occurred prior to the first CSA share distribution during each of two years. Members voluntarily enrolled in the study and completed a written pre-season survey at the time of their first CSA share pick-up. Study participants were recruited prior to each of two CSA seasons and data were collected via electronically administered surveys after the initial paper version.

To ensure inclusion of low-income CSA members in our sample, we collaborated with a local Cooperative Extension programme that offers subsidies for CSA memberships to households eligible for the Supplemental Nutrition Assistance Program (SNAP) or the Special Supplemental Nutrition Assistance Program for Women, Infants, and Children (WIC). The extension programme covered about half of the \$US 500 share price and participants paid the remaining \$US 250 in monthly instalments, using cash or SNAP benefits. Programme staff actively recruited study participants from community members who applied for and received the CSA subsidy.

Weekly shares were available for collection by participants over approximately 24 weeks, into late November. The composition and quantity of each weekly share was determined by the farmer and was based on availability and seasonality. Typically each weekly share contained between eight and twelve different items.

The study was conducted according to the guidelines laid down in the Declaration of Helsinki and the Cornell University Institutional Review Board approved all procedures involving human subjects. Written consent was obtained from 
all participants prior to implementation of the first survey and implied consent was obtained prior to completion of subsequent online surveys. Smith Lever and Hatch Federal Formula Funds were used to support this project.

\section{Survey administration and design}

Data collection occurred over two CSA seasons, defined as the period beginning the week before the first CSA share distribution and extending through the following February. Three surveys were administered in two CSA seasons as follows: (i) before the first CSA share pickup (PreCSA); (ii) immediately following the CSA season (Post-CSA); and (iii) three months after the end of the CSA season (Midwinter). After the initial paper version, subsequent surveys were administered online using Survey Monkey, a publically available online survey tool (www.surveymonkey.com/). CSA subsidy programme administrators, selected CSA managers, current and former CSA members, CSA farmers and managers, and academic Community Nutrition colleagues provided input on surveys. The surveys were revised and finalized based on these reviews.

Survey components at each data collection point included: (i) sociodemographic characteristics (Pre-CSA); (ii) vegetable consumption frequency of thirty specific vegetables (Pre-CSA, Post-CSA, Mid-winter); (iii) perceived changes in daily servings of vegetables (Post-CSA, Mid-winter); (iv) vegetables tried for the first time and changes in preferences (Post-CSA); (v) changes in selected food-related behaviours possibly affected by membership (Post-CSA); and (vi) intention to eat more vegetables year-round (Post-CSA).

Existing validated, brief survey measures of fruit and vegetable intake ${ }^{(27)}$ include a limited number (from four to eleven) of vegetables or vegetable categories and as such do not adequately represent the diversity offered by a CSA in the study area. Since we wished to explore specific changes in intake of a wide variety of vegetables and development of new preferences, our assessment of vegetable intake needed to reflect diversity typical of local CSA shares. We developed our vegetable frequency list based on historic reports of offerings by CSA managers plus observations and vegetable production data collected at other New York State and Northeast CSA farms by one co-author. The resulting vegetable list in our survey instrument was similar to one used in a study of CSA members in the Research Triangle Region of North Carolina, which contained vegetables typically grown in that study region ${ }^{(28)}$. Inclusion of colour pictures of vegetables, alongside the list of vegetables names, helped study participants complete the frequency measure and more easily identify vegetables tried for the first time.

\section{Data analysis}

Survey data were analysed with the statistical software package SPSS for Windows version 17.0 (2008); $P \leq 0.05$ was considered statistically significant. Analysis was conducted on data from all respondents pooled from both years and categorized by member status (new or returning) and by income category. Because all study participants with subsidized shares reported household incomes of \$US 30000 or less, \$US 30000 was used as the cut-off to categorize participants as 'lower-income' compared with those of 'higher-income'. Every participant contributed information on the Pre-CSA and on at least one of the two additional surveys. Quantitative frequencies, $\chi^{2}$ and Fisher's exact tests were used to analyse participant characteristics, attitudes and vegetable consumption measures.

The thirty-vegetable frequency measure was included in each survey (Pre-CSA, Post-CSA, Mid-winter) and data were analysed using multilevel linear regression models. Fixed effects included: project year, season, new or continuing membership, income, and interaction of new or returning membership with season. For vegetables infrequently eaten, consumption was dichotomized (eaten/not eaten during the previous week) and generalized estimating equation models with a binomial distribution and logit link were used to analyse responses. Non-significant fixed effects with $P \geq 0.05$ were removed in the final models. Significant effects were further examined using post hoc multiple comparisons with Tukey correction. New vegetables tried and changes in preferences and behaviours were analysed using frequencies and $t$, Wilcoxon, $\chi^{2}$ and Fisher's exact tests, as appropriate.

\section{Results}

Analysis was based on responses from 151 of the initial sample of 218 CSA members who agreed to participate in

Table 1 Sample characteristics of the study participants: CSA members $(n 151)$ from a rural county in New York, USA

\begin{tabular}{lrr}
\hline & $n$ & $\%$ \\
\hline Gender & 131 & \\
Female & 20 & 87 \\
Male & 13 \\
Race/ethnicity & 10 & 7 \\
Black & 8 & 5 \\
Asian & 123 & 82 \\
White & 6 & 4 \\
Mixed & 2 & 1 \\
Latino & 2 & 1 \\
Unknown & & \\
Income & 36 & 24 \\
$\quad$ \$US 30 000 & 98 & 65 \\
Z\$US 30 000 & 17 & 11 \\
Unknown & & \\
Number of children & 68 & 45 \\
None & 32 & 21 \\
One & 36 & 10 \\
Two or more & 15 & \\
Unknown & & 36 \\
Member status & 55 & 64 \\
New & 96 & 17 \\
Returning & 26 & 83 \\
Subsidized or full-paying members & & \\
Subsidized & 125 & \\
Full-paying & & \\
\hline
\end{tabular}

CSA, community-supported agriculture. 
the study. Only those who completed the Pre-CSA and one or both of the Post-CSA and Mid-winter surveys in the same CSA season were retained: eighty-one completed all three surveys in the same CSA season; fifty-nine completed Pre- and Post-CSA; and eleven people completed Pre-CSA and Mid-winter but not the Post-CSA. Those who completed only the Pre-CSA survey were excluded from the analysis. Comparisons were made between the data points for the full sample and, for selected items, between new and returning membership status and income level categories.

\section{Participant characteristics}

Respondent characteristics are shown in Table 1. Respondents were primarily female (87\%), white (81\%), had incomes greater than or equal to \$US 30000 (65\%), no children ( $45 \%$ ), had previously participated ('returning') in a CSA (64\%) and paid full price for their share (83\%). The $\chi^{2}$ and Fisher's exact tests showed that the sixty-seven participants who completed the Pre-CSA survey only (and were therefore excluded from the analysis) were similar to those who completed at least two surveys in age, race/ ethnicity and number of children, but were significantly

Table 2 Differences in weekly vegetable consumption during the CSA cycle (pre-CSA, post-CSA and Mid-winter) among CSA members ( $n$ 151) from a rural county in New York, USA

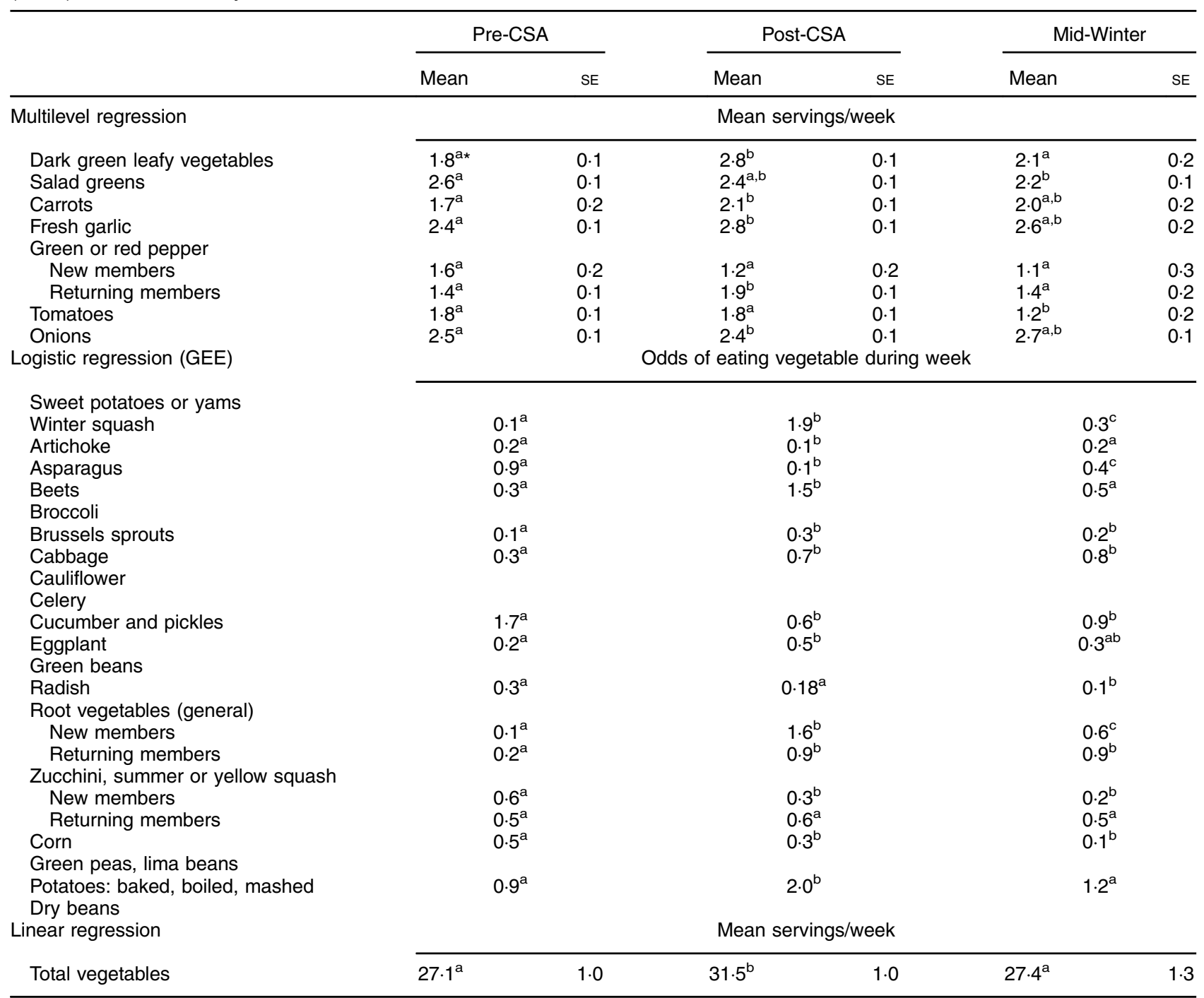

CSA, community-supported agriculture; GEE, generalized estimating equation.

Predicted means and odds are controlled for by project year, season, new or continuing membership, income, and interaction of new or returning membership with season (if significant).

${ }^{*}$ Significant difference notation: superscript letters $\left({ }^{\mathrm{a}, \mathrm{b}, \mathrm{c}}\right)$ are used to denote differences and similarities between pairs of mean servings/week. Three possible pairing exist for these data: Pre-CSA and Post-CSA; Post-CSA and Mid-Winter; and Pre-CSA and Mid-Winter. Differences between values sharing the same letter (e.g. between $1.6^{\mathrm{a}}$ and $\left.1.2^{\mathrm{a}}\right)$ are not statistically significant $(P>0.05)$. For differences between values that are significant $(P \leq 0.05)$ the superscript letters are different (e.g. between $1.8^{\mathrm{a}}$ and $\left.2 \cdot 8^{\mathrm{b}}\right)$. Where significant differences exist between all three possible pairings, all letters $\left({ }^{\mathrm{a}, \mathrm{b}, \mathrm{c}}\right)$ are present $\left(\mathrm{e} . \mathrm{g} .0 .1^{\mathrm{a}}, 1.6^{\mathrm{b}}\right.$ and $\left.0.6^{\mathrm{C}}\right)$. For each vegetable, seasonal intake means that do not share a letter in common are significantly different from each other $(P \leq 0.05)$. Rows left blank indicate no significant differences were found between time point pairings. 
more likely to be men $(P=0.001)$, new members $(P=0.001)$ and to have lower or unreported incomes $(P=0.002)$.

\section{Vegetable consumption differences before, after and between CSA seasons}

Comparisons of weekly servings consumed were made between Pre-CSA and Post-CSA, Post-CSA and Mid-Winter, and between Pre-CSA and Mid-Winter. Significance differences in weekly servings between time point pairs are indicated with superscript letters a, b and c in Table 2 (see footnote for explanation). Values in pairings with letters in common are not significantly different, whereas those pairings with different letters are significantly different.

Comparison of data from the Pre-CSA and Post-CSA surveys revealed a significant increase in weekly consumption for eleven of thirty specific vegetables: dark leafy greens, carrots, garlic, onions, winter squash, beets, Brussels sprouts, cabbage, eggplant, root vegetables and potatoes (Table 2). Returning, but not new, members also significantly increased their intake of green or red peppers. Total mean weekly intake of the thirty vegetables combined increased significantly from Pre-CSA (27.1 servings/week) to Post-CSA (31.5 servings/week), then returned to Pre-CSA level by Mid-winter (27.4 servings/week).

Post-CSA survey data revealed a decreased consumption of four vegetables (artichoke, asparagus, cucumbers/ pickles and corn) from Pre-CSA among all participants ( $P \leq 0.05$; Table 2). Consumption of zucchini, summer or yellow squash decreased among new members only. Mean weekly consumption Mid-winter was significantly higher than Pre-CSA for four winter storage vegetables (winter squash, Brussels sprouts, cabbage and root vegetables) among all respondents.
In the Post-CSA retrospective post/pre measure, the reported mean daily servings of vegetables consumed 'after CSA' (mean 3.5 (SD 1.2)) was significantly higher than 'before CSA' (mean 2.7 (SD 1.4); $P \leq 0.001 ; n$ 97; data not shown). Mid-winter, participants reported significantly higher mean daily vegetable servings 'during CSA' (mean $3 \cdot 1$ (sD 1.2)) than 'now' (mean 1.9 (sD 1.3); $P \leq 0.001 ; n 90$; data not shown). However, lower-income members reported significantly lower mean daily household servings of vegetables 'now' (mean 1.8 (SD 1.2)) than did higher-income members (mean 2.5 (sD 1.5); $P=0.043$; $n$ 75; data not shown).

\section{Trying new vegetables and acquiring preferences}

Post-CSA, nearly $60 \%$ ( $n$ 81) of participants who completed the post-CSA survey reported trying at least one, and up to eleven, new vegetables during the CSA season (Table 3). Within this group of participants, the mean number of new vegetables tried was 3.7 (SD 2.8; data not shown). New members tried significantly more $(P=0.002)$ new vegetables (mean 4.8 (SD 3.0)) than returning members (mean 2.9 (SD 2.3)). There was no significant difference in trial of new vegetables between the lower- and higher-income groups. Eleven vegetables (bokchoi, broccoli raab, celeriac, collards, daikon, fennel, kale, parsnips, rutabaga, Swiss chard and turnips) were tried for the first time by over $10 \%$ of all participants. Post-CSA, $52 \%$ ( $n 73)$ participants named at least one, and up to seven, different vegetables 'liked now but not before CSA participation' (Table 4). Of the thirty-one different vegetables for which new preferences developed, those mentioned by more than $5 \%$ of participants were beets, collards, greens, kale, Swiss chard, turnips and winter squash.

Mid-winter, forty-two (46\%) participants named twentyeight different vegetables new to them during the CSA that

Table 3 New vegetables tried and number of participants trying each for the first time during the CSA season $(N 140)^{\star}$ among CSA members $(n 151)$ from a rural county in New York, USA

\begin{tabular}{|c|c|c|c|c|c|}
\hline Vegetable first tried & No. of participants & $\%$ of participants & Vegetable first tried & No. of participants & $\%$ of participants \\
\hline Arugula & 12 & 8.6 & Green beans & 1 & 0.1 \\
\hline Basil & 4 & $2 \cdot 9$ & Hot peppers & 3 & $2 \cdot 1$ \\
\hline Beets & 13 & $9 \cdot 3$ & Kale & 18 & $12 \cdot 9$ \\
\hline Bokchoi & 18 & $12 \cdot 9$ & Leeks & 11 & 7.9 \\
\hline Broccoli & 1 & 0.1 & Mint & 1 & 0.1 \\
\hline Broccoli raab & 15 & $10 \cdot 7$ & Parsnips & 16 & 11.4 \\
\hline Brussels sprouts & 4 & 2.9 & Peppers & 1 & 0.1 \\
\hline Cabbage & 2 & 1.4 & Pumpkins & 2 & 1.4 \\
\hline Celeriac & 30 & 21.4 & Radishes & 2 & 1.4 \\
\hline Cilantro & 2 & 1.4 & Rutabaga & 18 & $12 \cdot 9$ \\
\hline Cucumber & 1 & 0.1 & Sage & 2 & 1.4 \\
\hline Collards & 17 & $12 \cdot 1$ & Salad mix & 2 & 1.4 \\
\hline Daikon & 20 & 14.3 & Summer squash & 2 & 1.4 \\
\hline Dill & 1 & 0.1 & Swiss chard & 17 & $12 \cdot 1$ \\
\hline Eggplant & 4 & 2.9 & Turnips & 23 & $16 \cdot 4$ \\
\hline Fennel & 34 & $24 \cdot 3$ & Winter squash & 8 & 5.7 \\
\hline
\end{tabular}

CSA, community-supported agriculture.

${ }^{*}$ Eighty-one participants $(57.9 \%)$ who completed the post-CSA survey reported trying at least one, and up to eleven, new vegetables during the CSA season. 
Table 4 New vegetable preference acquisitions as reported by participants at Post-CSA time point and sustained new vegetable enjoyment reported at Mid-Winter time point among CSA members ( $n$ 151) from a rural county in New York, USA

\begin{tabular}{|c|c|c|c|c|}
\hline \multirow[b]{2}{*}{ Vegetable } & \multicolumn{2}{|c|}{$\begin{array}{l}\text { Like now, but not } \\
\text { before CSA } \\
\text { (Post-CSA) } \\
(N 140)\end{array}$} & \multicolumn{2}{|c|}{$\begin{array}{l}\text { New during CSA, } \\
\text { continue to eat, enjoy } \\
\text { (Mid-Winter) } \\
(N 92)\end{array}$} \\
\hline & $n$ & $\%$ & $n$ & $\%$ \\
\hline Arugula & 6 & 4.3 & - & - \\
\hline Basil & 2 & 1.4 & - & - \\
\hline Beets & 16 & 11.4 & 4 & 4.4 \\
\hline Bokchoi & 4 & 2.9 & 3 & 3.3 \\
\hline Braising mix & 4 & 2.9 & - & - \\
\hline Broccoli & - & - & 2 & $2 \cdot 2$ \\
\hline Broccoli raab & 5 & 3.6 & - & - \\
\hline Brussels sprouts & 2 & 1.4 & - & - \\
\hline Cabbage & 3 & $2 \cdot 1$ & 1 & $1 \cdot 1$ \\
\hline Carrots & - & - & 2 & $2 \cdot 2$ \\
\hline Cauliflower & 1 & 0.7 & - & - \\
\hline Celeriac & 6 & 4.3 & 11 & $12 \cdot 0$ \\
\hline Cilantro & 3 & $2 \cdot 1$ & 1 & $1 \cdot 1$ \\
\hline Collards & 8 & $5 \cdot 7$ & 3 & $3 \cdot 3$ \\
\hline Corn & 1 & 0.7 & - & - \\
\hline Cucumber & 1 & 0.7 & 1 & $1 \cdot 1$ \\
\hline Daikon & 1 & 0.7 & 1 & $1 \cdot 1$ \\
\hline Edaname & 1 & 0.7 & - & - \\
\hline Eggplant & 3 & $2 \cdot 1$ & 2 & $2 \cdot 2$ \\
\hline Escarole & - & - & - & - \\
\hline Fennel & 8 & $5 \cdot 7$ & - & - \\
\hline Garlic & - & - & 1 & $1 \cdot 1$ \\
\hline Garlic scapes & 1 & 0.7 & 1 & $1 \cdot 1$ \\
\hline Greens & 8 & $5 \cdot 7$ & 8 & 8.7 \\
\hline Kale & 15 & $10 \cdot 7$ & 9 & $9 \cdot 8$ \\
\hline Kohlrabi & 4 & $2 \cdot 9$ & 8 & $8 \cdot 7$ \\
\hline Leeks & 3 & $2 \cdot 3$ & 1 & $1 \cdot 1$ \\
\hline Lettuce & - & - & 1 & $1 \cdot 1$ \\
\hline Mizuna & - & - & 1 & $1 \cdot 1$ \\
\hline Parsnips & 4 & 2.9 & 3 & 3.3 \\
\hline Peppers & 1 & 0.7 & - & - \\
\hline Pumpkin & 1 & 0.7 & - & - \\
\hline Radishes & 1 & 0.7 & - & - \\
\hline Rutabaga & 2 & 1.4 & 1 & $1 \cdot 1$ \\
\hline Spinach & - & - & 1 & $1 \cdot 1$ \\
\hline Sweet potato & - & - & 1 & $1 \cdot 1$ \\
\hline Swiss chard & 11 & $7 \cdot 9$ & 3 & $3 \cdot 3$ \\
\hline Tatsoi & - & - & 1 & $1 \cdot 1$ \\
\hline Tomatoes & - & - & 1 & $1 \cdot 1$ \\
\hline Turnips & 17 & $12 \cdot 1$ & 1 & $1 \cdot 1$ \\
\hline Winter squash & 8 & $5 \cdot 7$ & 1 & $1 \cdot 1$ \\
\hline
\end{tabular}

CSA, community-supported agriculture.

they continued to eat and enjoy (Table 4). Most often mentioned were celeriac, greens, kale and kohlrabi.

\section{Discussion}

Vegetable intake in the USA is generally limited in overall quantity and diversity. Potatoes and tomatoes (fresh and processed) account for nearly one-third of total per capita vegetable consumption ${ }^{(29)}$. These, together with lettuce, carrots, broccoli, onions, sweetcorn, snap beans, cucumbers, spinach, green peas and celery, make up $80 \%$ of total vegetable intake. Although the remaining $20 \%$ of total vegetables consumed includes over seventy other vegetables, most are consumed in very small amounts and/or by very few people ${ }^{(29)}$.

While the CSA strategy was originally conceived of as a way to strengthen economic and social ties among smallscale farmers and consumers, the model shows promise for increasing vegetable consumption and addressing disparities in food security. CSA members in our study significantly increased the amount and variety of some of these 'other' vegetables eaten. Throughout the season, CSA members become more aware of seasonality and local varieties. The social aspect of CSA may also help encourage members to try new vegetables and preparation methods.

Acquiring new vegetable preferences has particular relevance for public health and for developing and sustaining local food systems. Given the importance of vegetables to public health and the limited diversity of vegetables consumed, acquiring and expanding vegetable preferences can lead to improved nutrient intake. Further, expanding and diversifying vegetable preferences may increase food security among low-income consumers. Sandholtz and Price suggest that developing larger 'produce portfolios' may enable consumers to pay lower average prices for produce, by substituting away from expensive vegetables during price shocks ${ }^{(30)}$. Although all vegetables provide health benefits, those providing highest benefits include: dark green leafy vegetables, such as spinach, Swiss chard and mustard greens; cruciferous vegetables such as broccoli, cauliflower, cabbage, Brussels sprouts, bokchoi and kale; and deep yellow vegetables such as sweet potatoes and squashes ${ }^{(31)}$. Most, if not all, of these nutritionally important vegetables were commonly grown on CSA farms in the present study. Reported increased intake during the CSA season of over a third of the vegetables in the frequency list is consistent with other studies $^{(32)}$ and is not surprising as CSA participants received a share of vegetables each week. Increased consumption and reported first-time trial of dark green and orange vegetables is especially encouraging since underconsumption of these vegetables is well documented ${ }^{(33)}$.

The reported decrease in consumption of some specific vegetables could reflect a greater consumption of CSAprovided vegetables with consequent displacement of retail-purchased vegetables. For example, artichokes are not grown extensively in the Northeast and thus not typically included in a CSA share. Sweetcorn is rarely produced on organic CSA farms, because pest pressure reduces ear quality in the Northeast. Asparagus, an earlyseason crop, would likely be available before the typical CSA season. Week-to-week variability in vegetable availability throughout the CSA season may also have encouraged members to decrease or eliminate certain non-seasonal vegetables, such as summer squashes, once their harvest season ended. Seasonal variation in vegetable availability is a dominant aspect of the CSA experience that sets it apart from conventional retail experiences. 
Data from the mid-winter vegetable frequency measure indicate participants' reported consumption of winter squash, Brussels sprouts, cabbage and root vegetables remained significantly higher than before beginning the CSA season (Pre-CSA). Retention of these vegetables in the diet may reflect a sustained interest in eating what is locally and seasonally available. All of these vegetables can be stored and marketed during Northeast winter months and many are common in winter CSA shares. The elevated intake of all other vegetables observed post-CSA was not sustained by the Mid-winter survey, but had returned to pre-CSA levels. Eating foods that are produced locally during the harvest and availability period is consistent with how consumers conceptualize seasonal eating ${ }^{(34)}$.

CSA, along with farmers' markets, community kitchens, mobile meat processing units and consumer food cooperatives, are examples of 'civic agriculture' typified by locally organized systems of food production with networks of producers bound together by place ${ }^{(17)}$. Civic agriculture is considered an alternative to socially, economically and environmentally destructive practices often associated with conventional agriculture. CSA expose shareholders to vegetables that are available through such an alternative food system and increase awareness of seasonal availability. Augmenting vegetable preferences and increasing consumer willingness to vary vegetable intake seasonally can better align consumer demand with local food production, thus increasing local food system sustainability.

What is in season, however, may be changing in the study region. High tunnels, covered cold frames and other season-extension technologies are increasing seasonal availability of certain vegetables ${ }^{(35)}$. Such technologies make it possible to meet increasing consumer demand for locally grown produce and create an additional opportunity for farm viability ${ }^{(36)}$. When the present study began, we did not anticipate that lines between in- and out-ofseason produce would become blurred. Our original assumption that some vegetables (such as greens) would not be available from local sources at the Mid-winter time point may be unfounded.

The reported lower daily vegetable servings consumed 'now' among lower- compared with higher-income participants may indicate the importance of the CSA share subsidy to augment limited food budgets. Given the perishability of fresh vegetables, economic loss associated with spoilage and waste, and the skills and time required to prepare them, investing a limited food budget on fresh vegetables can involve greater relative economic risk for low-income consumers. Andreatta et al. suggest that federal and state food assistance programmes can be leveraged to decrease barriers to CSA participation among low-income consumers ${ }^{(37)}$. One of the strengths of non-governmental subsidized CSA share schemes is that participants get to try unfamiliar vegetables and see if they and family members like them with less economic risk. Given diet-related health disparities associated with income it is important to explore a range of approaches to increase healthy food access. Quandt et al. suggest that CSA is a feasible strategy for providing fresh produce to under-resourced communities ${ }^{(38)}$.

Our findings about exposure to and subsequent liking of previously unfamiliar vegetables support research documenting that exposure, availability, familiarity and preferences are important determinants of vegetable consumption for children and adults alike ${ }^{(39-41)}$. CSA participation may provide an encouraging environment in which to experiment with unfamiliar vegetables. Further, since access to unfamiliar vegetables appears to have led to trying and liking them, increasing opportunities for such exposure may help stimulate consumer demand for greater variety in local and regional vegetable production.

Findings from the present study are consistent with other studies reporting an increase in vegetable intake and varieties consumed ${ }^{(42)}$ and in overall diet quality ${ }^{(43)}$. Landis et al. found that CSA members consumed significantly greater amounts of vegetables than non-member controls $^{(28)}$. Data in Landis et al.'s study were collected at one time point and a non-member control group was used for comparison. Our study considered the changes in vegetable intake associated with CSA participation over time. Although our study lacked a control group, participants acted as their own controls, as they reported vegetable intake before and after the CSA experience.

Several limitations to the present study warrant attention. Although farmers reported similar growing conditions, crop types and yields in both study years, we did not track the quantity of specific vegetables included in weekly shares. Year-to-year variation in yields and planting decisions could have influenced the amount and types of vegetables available and hence reported change in variety and quantity consumed.

Because a desire for fresh, locally grown and organic food is a key motivator to join a $\operatorname{CSA}^{(44)}$, study participants may have been more enthusiastic 'vegetable eaters' to begin with than the general population. Those who choose to join a CSA, regardless of subsidy options, may be more interested than those who do not in trying new vegetables and expanding preferences. Potential selection bias was not controlled for and limits our interpretation of the data. Another limitation relates to our aggregation of all respondent data. Because of this any differences in vegetable intake, exposure and preference that may have stemmed from being in a rural county $v$. an urban setting could not be assessed.

Despite careful selection of CSA with known share subsidy programmes, our sample of low-income participants was limited. This limited our ability to make definitive conclusions regarding the influence of CSA participation on vegetable access, diet quality and food security among low-income community members. The CSA share subsidy programme increased access to this source of fresh, seasonal and local vegetables for lowerincome members. Although the subsidy programme most 
likely appeals to people who are interested in health and want to eat more vegetables, some subsidized participants may have been motivated to join mainly because of the financial assistance provided. It is impossible, from our data, to separate the influence of CSA participation from such individual factors.

Different CSA vegetable share assembly strategies may yield different results in terms of vegetable intake and preference. Members of the CSA in the present study assembled their own shares according to quantity and volume guidelines provided by CSA managers. Members had some choice among types or quantity of certain vegetables. In other CSA, managers may completely specify share contents, thus potentially exposing members to items that they would otherwise avoid, and further increasing opportunities to expand preferences.

Our thirty-vegetable frequency measure was constructed prior to the start of the CSA season and kept constant throughout the data collection to assure comparability. Changes in consumption of any additional vegetables provided by the CSA would have therefore been missed. More accurate descriptions of vegetable familiarity and change in quantity and variety consumed would have been possible by presenting members with a list of the specific vegetables grown by their CSA farmers. Further, our measure of vegetable frequency has not been validated. Finally, since we did not ask respondents to identify the source of vegetables they reported consuming, it is uncertain whether changes in consumption were due entirely to the CSA experience.

\section{Conclusion}

CSA participation was associated with increased consumption of vegetables among CSA members, whether new or returning, and regardless of household income. Given disparities in diet quality and higher incidence of diet-related diseases among lower-income groups, enhancing CSA participation among individuals with lower incomes may offer an effective strategy for increasing the quantity and variety of vegetables they consume. CSA share subsidizing mechanisms may be worthy of public support and commitment of tax dollars. The CSA members in our study could pay the remainder of their share cost in monthly instalments using part of their SNAP benefits. Extending the delivery of CSA shares into the winter season to include more storage crops may help retain total vegetable intake levels similar to those observed post-CSA. Results of the study suggest that increasing access to vegetables through alternative marketing and social structures such as CSA holds promise for improving diet quality in general and increasing vegetable variety and quantity in particular. Further, increasing liking for vegetables available seasonally through CSA participation can better align consumer preferences with production in local food systems.

\section{Acknowledgements}

Acknowledgements: The authors wish to thank Tompkins County Cooperative Extension for facilitating collaboration between study investigators and CSA farmers and managers. In particular they acknowledge critical contributions made by Elizabeth Karabinakis in low-income participant recruitment and in communication and coordination with participating CSA farmers. The authors wish to extend deep thanks to Françoise Marie Vermeylen for her statistical advice. Special thanks also go to the participating CSA managers and farmers for their assistance in study participant recruitment by providing access to their CSA members through email communication and on-site contact. Financial support: This work was supported by a joint research and extension programme funded by the Cornell University Agricultural Experiment Station (Hatch funds) and Cornell Cooperative Extension (Smith Lever funds) received from the National Institutes for Food and Agriculture (NIFA), US Department of Agriculture. Any opinions, findings, conclusions or recommendations expressed in this publication are those of the author(s) and do not necessarily reflect the view of the US Department of Agriculture. Conflict of interest: None. Authorship: J.L.W. served as principal investigator and provided oversight on all aspects of the project including research design, survey instrument development, data collection and analysis, and publication preparation. T.J.F. was primarily responsible for data management and analysis, liaising with the statistician and assisting with manuscript preparation; A.R. assisted in survey instrument development, coordinated survey implementation in the urban CSA site, provided horticultural expertise and assisted with the interpretation of findings. Ethics of buman subject participation: The study was conducted according to the guidelines laid down in the Declaration of Helsinki and all procedures involving human subjects were approved by the Cornell University Institutional Review Board. Written consent was obtained from all participants prior to implementation of the first survey and implied consent was obtained by completion of subsequent online surveys.

\section{References}

1. Centers for Disease Control and Prevention (2013) State Indicator Report on Fruits and Vegetables. Atlanta, GA: CDC, US Department of Health and Human Services; available at http://www.cdc.gov/ nutrition/downloads/State-Indicator-Report-FruitsVegetables-2013.pdf

2. Guenther PM, Dodd KW, Reedy J et al. (2006) Most Americans eat much less than recommended amounts of fruits and vegetables. J Am Diet Assoc 106, 1371-1379.

3. US Department of Agriculture \& US Department of Health and Human Services (2010) Dietary Guidelines for Americans, 2010, 7th ed. Washington, DC: US Government Printing Office; available at www.dietaryguidelines.gov 
4. Dubowitz T, Heron M, Bird CE et al. (2008) Neighborhood socioeconomic status and fruit and vegetable intake among whites, blacks, and Mexican Americans in the United States. Am J Clin Nutr 87, 1883-1891.

5. Lallukka T, Pitkäniemi J, Rahkonen O et al. (2010) The association of income with fresh fruit and vegetable consumption at different levels of education. Eur J Clin Nutr 64, 324-327.

6. Bowman S (2007) Low economic status is associated with suboptimal intakes of nutritious foods by adults in the National Health and Nutrition Examination Survey 1999-2002. Nutr Res 27, 515-523.

7. World Cancer Research Fund/American Institute for Cancer Research (1997) Food, Nutrition and the Prevention of Cancer: A Global Perspective. Washington, DC: American Institute for Cancer Research.

8. Riboli E \& Norat T (2003) Epidemiologic evidence of the protective effect of fruit and vegetables on cancer risk. $A m \mathrm{~J}$ Clin Nutr 78, 3 Suppl., 559S-569S.

9. He FJ, Nowson CA \& MacGregor GA (2006) Fruit and vegetable consumption and stroke: meta-analysis of cohort studies. Lancet 367, 320-326.

10. Steffen LM, Jacobs DR, Stevens J et al. (2003) Associations of whole-grain, refined-grain, and fruit and vegetable consumption with risks of all-cause mortality and incident coronary artery disease and ischemic stroke: the Atherosclerosis Risk in Communities (ARIC) Study. Am J Clin Nutr 78, 383-390.

11. Dauchet L, Amouyel P, Hercberg S et al. (2006) Fruit and vegetable consumption and risk of coronary heart disease: a meta-analysis of cohort studies. J Nutr 136, 2588-2593.

12. Ford ES \& Mokdad AH (2001) Fruit and vegetable consumption and diabetes mellitus incidence among US adults. Prev Med 32, 33-39.

13. DeMuth S (1993) Community Supported Agriculture (CSA): An Annotated Bibliography and Resource Guide. US Department of Agriculture, Alternative Farming Systems Information Center (AFSIC). http://www.nal.usda.gov/afsic/ pubs/csa/csadef.shtm (accessed December 2014).

14. McFadden S (2012) Unraveling the CSA number conundrum. Blog post, The Call of the Land: An Agrarian Primer for the 21st Century. http://thecalloftheland.wordpress. com/2012/01/09/unraveling-the-csa-number-conundrum/ (accessed December 2014).

15. Guthman J, Morris AW \& Allen P (2006) Squaring farm security and food security in two types of alternative food institutions. Rural Sociol 71, 662-684.

16. Feenstra G (1997) Local food systems and sustainable communities. Am J Altern Agric 12, 28-36.

17. Lyson TA (2004) Civic Agriculture: Reconnecting Farm. Food, and Community. Lebanon, NH: Tufts University Press.

18. Allen P, Guthman J \& Morris AW (2006) Meeting Farm and Food Security Needs through Community Supported Agriculture and Farmers' Markets in California. Research Brief \#9, Fall 2006. Santa Cruz, CA: Center for Agroecology and Sustainable Food Systems, University of California, Santa Cruz; available at http://casfs.ucsc.edu/documents/researchbriefs/RB_9_food_security.pdf

19. Ostrom MR (2007) Community supported agriculture as an agent of change. Is it working? In Remaking the North American Food System - Strategies for Change, pp. 99-120 [CC Hinrichs and AT Lyson, editors]. Lincoln, NE: University of Nebraska Press.

20. Hinrichs CC (2000) Embeddedness and local food systems: notes on two types of direct agricultural market. J Rural Stud 16, 295-303.

21. Cooley JP \& Lass DA (2012) Consumer benefits from community supported agriculture membership. Rev Agric Econ 20, 227-237.

22. Goland C (2002) Community supported agriculture, food consumption patterns, and member commitment. Cult Agric 24, 14-25.
23. Zajonc RB (1968) Attitudinal effects of mere exposure. J Pers Soc Psychol 9, 1-27.

24. Pliner $\mathrm{P}$ (1982) The effects of mere exposure on liking for edible substances. Appetite 3, 283-290.

25. Pliner P, Pelchat M \& Grabski M (1993) Reduction of neophobia in humans by exposure to novel foods. Appetite 20, 111-123.

26. Casagrande SS, Wang Y, Anderson C et al. (2007) Have Americans increased their fruit and vegetable intake? The trends between 1988 and 2002. Am J Prev Med 32, 257-263.

27. Kim DJ \& Holowaty EJ (2003) Brief, validated survey instruments for the measurement of fruit and vegetable intakes in adults: a review. Prev Med 36, 440-447.

28. Landis B, Smith TE, Lairson M et al. (2010) Communitysupported agriculture in the Research Triangle Region of North Carolina: demographics and effects of membership on household food supply and diet. J Hunger Envir Nutr $\mathbf{5}$, 70-84.

29. Peters CJ, Bills N, Wilkins JL et al. (2002) Vegetable Consumption, Dietary Guidelines and Agricultural Production in New York State - Implications for Local Food Economies. Research Bulletin no. 663KB. Ithaca, NY: Department of Applied Economics and Management, Cornell University.

30. Sandholtz W \& Price J (2014) The picky eater premium?: the effect of product portfolio size on the price consumers pay for fresh produce. I Undergrad Res Brigham Young Univ available at http://jur.byu.edu/?p=755

31. Hung HC, Joshipura KJ, Jiang R et al. (2004) Fruit and vegetable intake and risk of major chronic disease. $J$ Natl Cancer Inst 96, 1577-1584.

32. Uribe ALM, Winham DM \& Wharton CM (2012) Community supported agriculture membership in Arizona. An exploratory study of food and sustainability behaviors. Appetite 59, 431-436.

33. Dietary Guidelines Advisory Committee (2010) Appendix E-3.2 realigning vegetable subgroups: food pattern modeling analysis. In Report of the Dietary Guidelines Advisory Committee on the Dietary Guidelines for Americans, 2010, to the Secretary of Agriculture and the Secretary of Health and Human Services. Washington, DC: US Department of Agriculture, Agricultural Research Service.

34. Wilkins JL, Bowdish E \& Sobal J (2002) Consumer perceptions of seasonal and local foods: a study in a US community. Ecol Food Nutr 41, 415-439.

35. Bachmann J (2005) Season Extension Techniques for Market Gardeners. National Sustainable Agriculture Information Service (ATTRA). https://attra.ncat.org/attra-pub/summaries/ summary.php?pub=366 (accessed December 2014).

36. Conner DS, Montri AD, Montri DN et al. (2009) Consumer demand for local produce at extended season farmers' markets: guiding farmer marketing strategies. Renew Agric Food Syst 24, 251-259.

37. Andreatta S, Rhyne M \& Dery N (2008) Lessons learned from advocating CSAs for low-income and food insecure households. S Rural Sociol 23, 116-148.

38. Quandt SA, Dupuis J, Fish C et al. (2013) Feasibility of using a community-supported agriculture program to improve fruit and vegetable inventories and consumption in an underresourced urban community. Prev Chronic Dis 10, E136.

39. Blanchette L \& Brug J (2005) Determinants of fruit and vegetable consumption among 6-12-year-old children and effective interventions to increase consumption. J Hum Nutr Diet 8, 431-443.

40. Birch LL \& Marlin DW (1982) I don't like it; I never tried it: effects of exposure on two-year old children's food preferences. Appetite 3, 353-360.

41. Pollard J, Kirk SFL \& Cade JE (2002) Factors affecting food choice in relation to fruit and vegetable intake: a review. Nutr Res Rev 15, 373-387. 
42. Oberholtzer L (2012) Community Supported Agriculture in the Mid-Atlantic Region: Results of a Shareholder Survey and Farmer Interviews. Small Farm Success Project. http:// www.winrock.org/wallace/wallacecenter/documents/wc-CSA Report.pdf (accessed December 2014).

43. Perez J, Allen P \& Brown M (2012) Community Supported Agriculture on the Central Coast: The CSA Member Experience. Research Brief \#1, Winter 2003. Santa Cruz, CA:
Center for Agroecology and Sustainable Food Systems, University of California, Santa Cruz; available at http:// 63.249.122.224/wp-content/uploads/2010/04/Brief_1_CSA2. pdf

44. Brehm JM \& Eisenhauer BW (2008) Motivations for participating in community-supported agriculture and their relationship with community attachment and social capital. S Rural Sociol 23, 94-115. 